\title{
In Vitro Adsorption Studies of Paracetamol to Activated Charcoal Capsule, Powder and Suspension
}

\author{
Suresh Panthee ${ }^{1, *}$ and Shyam P. Lohani ${ }^{2}$ \\ ${ }^{I}$ Institute of Medicine, Maharajgunj, Kathmandu, Nepal and ${ }^{2}$ Nepal Drug and Poison Information Center, Kathmandu, \\ Nepal
}

\begin{abstract}
Introduction: Adsorption capacity of activated charcoal to paracetamol was determined at simulated gastric environment, $\mathrm{pH} 3.4$ and simulated intestinal environment $\mathrm{pH}$ 7.2. Three formulations of activated charcoal; powder, capsule and suspension were tested. Paracetamol was derived from tablet to simulate in vivo intoxication conditions.

Methods: Activated charcoal and paracetamol were mixed at both the pHs. The amount of activated charcoal was varied to obtain activated charcoal-paracetamol ratio from 10:1 to 1:1. Then the mixtures were shaken, filtered and the content of remaining paracetamol was determined by UV spectrophotometer.

Results: The maximal adsorption capacity, milligram of paracetamol adsorbed per gram of activated charcoal, was determined by using Langmuir adsorption isotherm. The maximal adsorption capacity [ $95 \%$ confidence intervals in square brackets] was 284.47 [221.50; 347.44] at $\mathrm{pH} 3.4$ and 303.03 [303.03; 303.03] at pH 7.2 for powder; 175.49 [133.79; 217.18 ] at $\mathrm{pH} 3.4$ and 213.23 [182.56; 243.90] at $\mathrm{pH} 7.2$ for capsule; and 254.27 [245.08; 263.47] at $\mathrm{pH} 3.4$ and 263.64 [229.13; 298.15] at $\mathrm{pH} 7.2$ for suspension. The effect of $\mathrm{pH}$ on adsorption capacity was not significant.

Discussion: Under simulated conditions, the three formulations of activated charcoal adsorbed sufficient amount of paracetamol. The data show that activated charcoal $1 \mathrm{~g} / \mathrm{kg}$ body weight is sufficient a poisoned patient from if given shortly after intoxication.
\end{abstract}

Key Words: Paracetamol, poisoning, activated charcoal, formulation, adsorption.

\section{INTRODUCTION}

Poisoning is one of the most common medical emergencies. For different reasons, the problem of poisoning is faced all over the world. Though the substances implicated for poisoning vary from country to country, use of drugs for poisoning is well documented in the developed and developing countries [1-8]. Use of paracetamol for self harm and poisoning is common in Nepal [6-7]. More of the poisoning cases are seen in the lower level hospitals where many facilities like specific antidote; Therapeutic Drug Monitoring (TDM); ventilatory support etc are lacking [7]. In such cases, use of best formulation of Activated Charcoal (AC) might be a successful measure to save lives. Maximal adsorption capacity (MAC) is defined as the miligrams of drug adsorbed per gram of activated charcoal. The knowledge of MAC of different formulations of $\mathrm{AC}$ for paracetamol will theoretically help to calculate adequate dose of $\mathrm{AC}$ in case of paracetamol poisoning to prevent the toxic effects.

$\mathrm{AC}$ is a product of controlled pyrolysis of organic material activated by heating in an oxidizing gas at high temperature. AC is used as a non specific gastrointestinal (GI) decontaminant in poisoning, is often used even if the poison has specific antidote. For this reason, easily re-suspendable and efficacious preparation of $\mathrm{AC}$ should be available in the

*Address correspondence to this author at the P.O. Box 1524, Institute of Medicine, Kathmandu, Nepal; Tel: +9779841386222;

E-mail: supanthee@gmail.com emergency rooms or nearby. Recently, three formulations; powder, oral suspension, and capsule with brand name DTox have been registered and marketed in Nepal. These three formulations contain AC with same surface area $1600 \mathrm{~m}^{2} / \mathrm{g}$. The previous studies [9-12] have shown that there is a difference in adsorption capacity with different formulations of AC. Also, only the unionized form of drug is adsorbed. So this study was performed at two different $\mathrm{pHs}$ (simulated gastric $\mathrm{pH}: 3.4$ and simulated intestinal $\mathrm{pH}: 7.2$ ) and the effect of $\mathrm{pH}$ on adsorption of paracetamol to AC was studied. Most of the previous in vitro studies [9-10, 13-16] used the drugs in pure form. In this study the paracetamol was derived from tablets to simulate in vivo intoxication.

\section{MATERIALS AND METHODS}

\section{Chemicals and Reagents}

Paracetamol tablets were obtained from local retail pharmacy. Three types of AC were tested. D-Tox powder contained AC $30 \mathrm{~g}$; D-Tox suspension contained $100 \mathrm{ml}$ of suspension with AC 20\% w/v and sorbitol 5\% w/v; and DTox capsule contained $280 \mathrm{mg}$ of AC per capsule. All other chemicals used were of analytical grade.

Gastric environment; buffer $\mathrm{pH} 3.4$ was prepared by taking $0.6803 \mathrm{~g}$ of sodium acetate and mixing with $5.7 \mathrm{ml}$ of glacial acetic acid and making the volume to $1000 \mathrm{ml}$ by adding water. Intestinal environment; buffer $\mathrm{pH} 7.2$ was prepared by dissolving $6.8045 \mathrm{~g}$ of Potassium Dihydrogen Or- 
thophosphate $\left(\mathrm{KH}_{2} \mathrm{PO}_{4}\right)$ and $1.388 \mathrm{~g}$ of Sodium Hydroxide $(\mathrm{NaOH})$ in water and making the volume to $1000 \mathrm{ml}$ with water.

\section{Apparatus}

All the glass apparatus were from Borosil; filter paper was 595 Round filter (similar to No 1) from Schleicher and Schuell; spectrophotometer was UV-1601PC from Shimadzu, Japan; analytical balance was AB 104-S from Mettler Toledo and $\mathrm{pH}$ meter was Hana $\mathrm{pH} 211$ Microprocessor $\mathrm{pH}$ meter.

\section{Charcoal Adsorption Studies}

Paracetamol tablets were crushed in a mortar and sifted through a sieve of 100 mesh. Powder equivalent to $250 \mathrm{mg}$ of paracetamol was weighed and dissolved in $500 \mathrm{ml}$ of study buffer (stock solution). The quantity of paracetamol in all experiments was $25 \mathrm{mg}$ and the quantity of AC was varied. To obtain a fit to Langmuir adsorption isotherm AC, paracetamol ratios were $10: 1,5: 1,3: 1,2: 1$, and 1:1. Three trials for each experiment were prepared.

AC 25, 50, 75, 125 and $250 \mathrm{mg}$ was weighed and each kept in $100 \mathrm{ml}$ beakers in which $50 \mathrm{ml}$ of stock solution was added. Then the mixtures were shaken for 15 minutes and allowed to remain still for 10 minutes. The mixtures were filtered through a filter paper by discarding the first $10 \mathrm{ml}$ portions. Then $1 \mathrm{ml}$ of the filtrate was taken and diluted to $50 \mathrm{ml}$ with buffer.

A standard solution was prepared by taking $100 \mathrm{mg}$ of paracetamol reference standard and dissolving it to $100 \mathrm{ml}$ with the study buffer and then one $\mathrm{ml}$ of the resulting solution was diluted to $100 \mathrm{ml}$ with the buffer.

The absorbance of both the solutions was measured at the wave length maximum of $244 \mathrm{~nm}$ in UV spectrophotometer and the content of paracetamol in each trial was calculated.

\section{Langmuir Adsorption Isotherm}

Langmuir adsorption isotherm was used to calculate the MAC of AC [9-11, 14, 17]. The Langmuir adsorption isotherm is expressed as:

$$
\mathrm{Q}=\mathrm{Q}_{\mathrm{m}} \mathrm{K} \mathrm{C} \mathrm{C}_{\mathrm{f}} /\left(1+\mathrm{K} \mathrm{C}_{\mathrm{f}}\right)
$$

The above equation can be rearranged to following linear form:

$$
\mathrm{C}_{\mathrm{f}} / \mathrm{Q}=\mathrm{C}_{\mathrm{f}} / \mathrm{Q}_{\mathrm{m}}+1 / \mathrm{KQ}_{\mathrm{m}}
$$

Where,

- $\mathrm{Q}(\mathrm{mg} / \mathrm{g})$ is $\mathrm{mg}$ of adsorbate per $\mathrm{g}$ of adsorbent; calculated as $\mathrm{Q}=\mathrm{V}\left(\mathrm{C}_{\mathrm{o}}-\mathrm{C}_{\mathrm{f}}\right) / \mathrm{W}$, where $\mathrm{V}$ is the total volume in litre and $\mathrm{W}$ the quantity of $\mathrm{AC}$ in grams; $\mathrm{C}_{\mathrm{o}}(\mathrm{mg} / \mathrm{L})$ is the initial paracetamol concentration in the stock solution assuming that all the paracetamol is dissolved, (quantity of paracetamol added, divided by V.)]

- $\mathrm{C}_{\mathrm{f}}$ is the concentration of adsorb ate in solution $\mathrm{mg} / \mathrm{L}$;

- $\mathrm{K}$ is Langmuir modal parameter

- $\mathrm{Q}_{\mathrm{m}}(\mathrm{mg} / \mathrm{g})$ is maximum adsorption capacity corresponding to complete monolayer coverage
The data obtained from each trial was fitted to equation 2 and maximal adsorption capacity was determined by plotting $\mathrm{C}_{\mathrm{f}} / \mathrm{Q}$ against $\mathrm{C}_{\mathrm{f}}$ where slope gave the value of $1 / \mathrm{Q}_{\mathrm{m}}$. A pilot study involving paracetamol raw material was performed before the final experiments.

\section{Statistical Analysis of Data}

Both univariate and multivariate analysis were used for analysis of the data. In univariate analysis mean, standard deviation, confidence interval etc were used. Multivariate analysis was done by using analysis of variance (ANOVA), post hoc tukey test and student's t-test. The value set for statistical significance was $\mathrm{p}<0.05$ using two-sided test. All the analysis was carried out by using software SPSS 11.5.

\section{RESULTS}

\section{Maximal Adsorption Capacity}

Langmuir adsorption isotherm was used to calculate the maximal adsorption capacity, $\mathrm{Q}_{\mathrm{m}}$.

Table 1. Maximal Adsorption Capacity, Qm (mg paracetamol adsorbed/g AC), of Paracetamol to Three Formulations of AC. All Data are Means of Three Trials, (95\% confidence limits)

\begin{tabular}{|c|c|c|}
\hline & & $\mathbf{Q}_{\mathbf{m}}, \mathbf{m g}$ Paracetamol Adsorbed/g of AC \\
\hline \hline \multirow{2}{*}{ pH 3.4 } & Powder* & $284.47[221.50 ; 347.44]$ \\
\cline { 2 - 3 } & Suspension* & $254.27[245.08 ; 263.47]$ \\
\cline { 2 - 3 } & Capsule* $^{*}$ & $175.49[133.79 ; 217.18]$ \\
\hline \multirow{2}{*}{ pH 7.2 } & Powder $^{\#}$ & $303.03[303.03 ; 303.03]$ \\
\cline { 2 - 3 } & Suspension $^{\#}$ & $263.64[229.13 ; 298.15]$ \\
\cline { 2 - 3 } & Capsule $^{\#}$ & $213.23[182.56 ; 243.90]$ \\
\hline
\end{tabular}

* Different from each other at significance level $0.05, \mathrm{p}=0.001$.

${ }^{*}$ Different from each other at significance level $0.05, \mathrm{p}=0.000$.

Maximal adsorption capacity of three different formulations at two different pHs is shown in the Table 1. The adsorption capacity of three formulations was significantly different from each other at both the pHs. $\left(\mathrm{F}_{2,6}=30.38\right.$ and $\mathrm{p}$ $=0.000$ for $\mathrm{pH} 3.4$ and $\mathrm{F}_{2,6}=52.80$ and $\mathrm{p}=0.001$ for $\mathrm{pH}$ 7.2)

Post hoc tukey test (HSD) showed that there was significant difference among the maximal adsorption capacity of three different formulations as shown in Table $\mathbf{2}$ except in case of powder and suspension at pH 3.4 ( $\mathrm{p}>0.05)$

\section{Effect of pH on MAC}

The effect of $\mathrm{pH}$ on the adsorption capacity was analysed by using paired student's t- test. Mean difference between the adsorption capacities at two different pHs (7.2 and 3.4) was not significant. $\left(t_{2}=1.49\right.$ and $p=0.276$ for suspension; $t_{2}=$ 1.27 and $\mathrm{p}=0.332$ for powder; and $\mathrm{t}_{2}=3.43$ and $\mathrm{p}=0.076$ for capsule). 
Table 2. Difference of MAC between Individual Formulations at Different pH as Determined by Post Hoc Tukey Test. Data are Shown as Mean Difference (95\% confidence limits)

\begin{tabular}{|c|c|c|c|c|}
\hline & & & Mean Difference & p value \\
\hline \hline \multirow{3}{*}{ pH 3.4 } & Powder & Suspension & $30.20[-14.10 ; 74.50]$ & 0.172 \\
\cline { 2 - 5 } & Powder & Capsule & $108.99^{*}[64.69 ; 153.29]$ & 0.001 \\
\cline { 2 - 5 } & Suspension & Capsule & $78.79^{*}[34.49 ; 123.09]$ & 0.004 \\
\hline \multirow{3}{*}{ pH 7.2 } & Powder & Suspension & $39.39^{*}[12.51 ; 6.27]$ & 0.010 \\
\cline { 2 - 5 } & Powder & Capsule & $89.80^{*}[62.92 ; 116.68]$ & 0.000 \\
\cline { 2 - 5 } & Suspension & Capsule & $50.41^{*}[23.53 ; 77.29]$ & 0.003 \\
\hline
\end{tabular}

* The mean difference is significant at the .05 level.

Langmuir plots (not shown here) showed good linearity in all cases $\left(R^{2}>0.9962\right)$. This indicates that the data fit well to the langmuir adsorption isotherm.

\section{DISCUSSION}

The adsorption studies were performed at two $\mathrm{pHs}$ to simulate the environment in GI tract (3.4 and 7.2). To achieve saturation of AC with paracetamol, the amount of $\mathrm{AC}$ in each of the test was varied so that the ratios of mass of AC to paracetamol varied from 10:1 to 1:1. Paracetamol used was derived from the tablets in order to simulate in vivo intoxication conditions where the patient takes the tablets available in the market.

The maximal adsorption capacity of AC to paracetamol was found to range from $175.49 \mathrm{mg} / \mathrm{g}$ to $303.03 \mathrm{mg} / \mathrm{g}$ of AC (Capsule pH 3.4 and powder $\mathrm{pH} 7.2$ respectively). The hepatotoxic dose of paracetamol is generally accepted to be $150 \mathrm{mg} / \mathrm{kg}[18,19]$. This indicates that $\mathrm{AC}$ at a dose of $1 \mathrm{~g} / \mathrm{kg}$ bodyweight is sufficient to prevent hepatotoxic effects of paracetamol in case of acute poisoning. The lower adsorption capacity of capsule may be because the AC in capsule was somewhat granular and some ingredients other than mentioned in the label might have been added during capsule filling process, which were not taken into consideration. If this data is extrapolated, AC, given within short time after intoxication, clinically used dose of AC $(50 \mathrm{~g})$ has the capacity to adsorb $8.77-15.15 \mathrm{~g}$ paracetamol (Capsule $\mathrm{pH} 3.4$ and powder $\mathrm{pH} 7.2$ respectively) which comes to be 17 to 30 tablets of 500mg. The amount of paracetamol adsorbed by $\mathrm{AC}$ can be different in case of other formulations rather than tablets as shown by Levy et al. [20].

Several in vitro studies investigate the adsorption capacity of different test substances to AC [9-11, 13-17]. In this study, it is found that $\mathrm{pH}$ had no effect on the adsorption capacity. This is in accordance with other in vitro studies performed with paracetamol $[9,10,14-16]$.

The maximal adsorption capacity of charcoal in this study was found to be less than that of previous studies [9$10,14]$. This might be because those studies were performed in AC with high surface area as compared to this study $1600 \mathrm{~m}^{2} / \mathrm{g}$ vs $2000 \mathrm{~m}^{2} / \mathrm{g}$ and there is positive correlation between the adsorption capacity and surface area of AC [9]. Also, this study was performed with paracetamol tablets where the excipients of the tablet might have affected the adsorption capacity. Amount of AC administered in actual poisoning should be more than the extrapolated value of in vitro studies because there might be interference from the other contents of stomach as well. This is also proved by different studies where food and ice cream [10] ; ethanol $[9,16]$ and yogurt $[14]$ reduced the adsorption capacity.

The adsorption experiments showed a higher adsorption capacity of powder followed by suspension and then by capsule $(p<0.05)$ for both the pHs. The variation is due to the excipients used in formulation. The result from this study is also in accordance with Remmert et al. where they have shown that suspension had maximal adsorption capacity followed by tablet and capsule to adsorb paracetamol in vivo [12]. Though it is said that capsule charcoal should not be used for poisoned cases, it is seen from this study that adsorption capacity of charcoal capsule might be sufficient to be used in poisoning cases if the charcoal is taken out of capsule shells before administering to the patient.

Easily re-suspendable and efficacious preparation of AC should be available in the emergency departments. Though, all these three formulations can be used for gastrointestinal decontamination, palatability of charcoal is also a problem during administration. The palatability of AC plays an important role in the administration. In a study, it is seen that $39 \%$ of overdosed patient refused to take the AC [2]. The substances used to make it palatable should not affect the adsorption capacity. The results of this study show that the adsorption capacity of a standard dose AC suspension is high and theoretically able to adsorb the paracetamol content from 25-26 paracetamol tablets (each containing $500 \mathrm{mg}$ paracetamol). If the patients accept to take more charcoal with sorbitol, it is acceptable to use this formulation. Also, suspension can be easily administered through nasogastric tube and there is no need of mixing with water before administration.

In summary, the extrapolation of this in vitro study shows that if $\mathrm{AC}$ is given within short time after intoxication, a standard treatment dose of $50 \mathrm{~g} \mathrm{AC}$ has the capacity to adsorb 8.77 - $15.15 \mathrm{~g}$ paracetamol (Capsule $\mathrm{pH} 3.4$ and powder $\mathrm{pH} 7.2$ respectively) which comes to lie between 17 and 30 tablets of paracetamol. This dose might be sufficient for the treatment of intoxications where patient takes near about this range of tablets. Though, administration of capsule will be somewhat tedious, any of these three formulations 
can be used to detoxify patient, but the best choice can be made by the physicians, patient and the patient party to administer the adequate dose of AC.

\section{Limitations of the Study}

The main drawback of the study is its in vitro nature. Though simulation of gastric and intestinal environment is done, there might be considerable difference in actual conditions as compared to this laboratory situation.

\section{REFERENCES}

[1] Srivastava A, Peshin SS, Kaleekal T, Gupta SK. An epidemiological study of poisoning cases reported to the National Poisons Information Centre, All India Institute of Medical Sciences, New Delhi. Hum Exp Toxicol 2005; 24: 279-285.

[2] Lynch RM, Robertson R. Activated charcoal: The untold story. Accid Emerg Nurs 2003; 11: 63-67.

[3] Hawton K, Ware C, Mistry H, et al. Why patients choose paracetamol for self poisoning and their knowledge of its dangers. BMJ 1995; 310:164.

[4] Hawton K, Fragg JG, Simkin S, Bale E, Bond A. Deliberate self harm in adolescents in Oxford, 1985-1995. J Adolesc 2000; 23: 4755 .

[5] Pathak UN, Chhetri PK, Dhungel S, et al. Retrospective study of poisoning cases admitted in Nepal Medical College Teaching Hospital. Nepal Med Coll J 2002; 3: 101-105.

[6] Ghimire RH, Sharma SP, Pandey KR. A retrospective study of changing trends of acute poisoning cases at Tribhuvan University Teaching Hospital, Nepal between 1990-1992 and 2000-2002. J Nepal Health Res Counc 2003; 3: 38-41.

[7] Ghimire RH, Sharma SP, Pandey KR. A comparative study of acute poisoning in Nepal at tertiary and secondary level hospitals. J Nepal Med Assoc 2004; 43: 130-133.

[8] Chakrabarti K, Devkota KC. Retrospective study of suicide cases admitted in Nepal Medical College Teaching Hospital. Nepal Med Coll J 2004; 6: 116-118

[9] Hoegberg LC, Angelo HR, Christophersen AB, Christensen HR. Effect of ethanol and $\mathrm{pH}$ on the adsorption of acetaminophen (paracetamol) to high surface activated charcoal, in vitro studies. J Toxicol Clin Toxicol 2002; 40: 59-67.

[10] Hoegberg LC, Angelo HR, Christophersen AB, Christensen HR. The effect of food and ice cream on the adsorption capacity of paracetamol to high surface activated charcoal: in vitro studies. Pharmacol Toxicol 2003; 93: 233-237.

[11] Dawling S, Chand S, Braithwaite RA, Crome P. In vitro and in vivo evaluation of two preparations of activated charcoal as adsorbents of aspirin. Hum Toxicol 1983; 2: 211-216.

[12] Remmert HP, Olling M, Slob W, van der Giesen WF, van Dijk A, Rauws AG. Comparative antidotal efficacy of activated charcoal tablets, capsules and suspension in healthy volunteers. Eur J Clin Pharmacol 1990; 39: 501-505.

[13] Raffa RB, Wu C, Stone DJ, Borenstein MR, Codd EE, Coogan TP Determination of the adsorption of tramadol hydrochloride by activated charcoal in vitro and in vivo. J Pharmacol Toxicol Methods 2000; 43: 205-210.

[14] Hoegberg LC, Christophersen AB, Christensen HR, Angelo HR. Comparison of the adsorption capacities of an activated-charcoalyogurt mixture versus activated-charcoal-water slurry in vivo and in vitro. Clin Toxicol (Phila) 2005; 43: 269-275.

[15] Teubner DJ. Absence of ice-cream interference with the adsorption of paracetamol onto activated charcoal. Emerg Med 2000; 12: 326328.

[16] Bailey DN, Briggs JR. The effect of ethanol and $\mathrm{pH}$ on the adsorption of drugs from simulated gastric fluid onto activated charcoal. Ther Drug Monit 2003; 25: 310-313.

[17] Hoffman RS, Stringer JA, Feinberg RS, Goldfrank LR. Comparative efficacy of thallium adsorption by activated charcoal, prussian blue, and sodium polystyrene sulfonate. J Toxicol Clin Toxicol 1999; 37: 833-837.

[18] Wallace CI, Dargan PI, Jones AL. Paracetamol overdose: An evidence based flowchart to guide management. Emerg Med J 2002; 19: 202-205.

[19] Dargan PI, Jones AL. Acetaminophen poisoning: An update for the intensivist. Crit Care 2002; 108-110.

[20] Levy G, Houston JB. Effect of activated charcoal on acetaminophen absorption. Pediatrics 1976; 58: 432-435. 